(C) [2007] IEEE. Reprinted, with permission, from [JianXun Jin, YouGuang Guo, JiaXin Chen, LuHai Zheng and JianGuo Zhu, HTS Levitation and Transportation with Linear Motor Control, Control Conference, 2007. CCC 2007. Chinese July 26 2007-June 31 2007]. This material is posted here with permission of the IEEE. Such permission of the IEEE does not in any way imply IEEE endorsement of any of the University of Technology, Sydney's products or services. Internal or personal use of this material is permitted. However, permission to reprint/republish this material for advertising or promotional purposes or for creating new collective works for resale or redistribution must be obtained from the IEEE by writing to pubs-permissions@ieee.org. By choosing to view this document, you agree to all provisions of the copyright laws protecting it 


\title{
HTS Levitation and Transportation with Linear Motor Control
}

\author{
JianXun $\mathrm{Jin}^{1}$, YouGuang Guo ${ }^{2}$, JiaXin Chen², LuHai Zheng ${ }^{1}$, JianGuo Zhu ${ }^{2}$ \\ 1. Center of Applied Superconductivity and Electrical Engineering, \\ University of Electronic Science and Technology of China, ChengDu, SiChuan, 610054 China \\ E-mail: jxjin@uestc.edu.cn \\ 2. Faculty of Engineering, University of Technology, Sydney, PO Box 123, Broadway, NSW 2007, Australia \\ E-mail: youguang@eng.uts.edu.au
}

\begin{abstract}
High temperature superconductor (HTS) bulk can produce strong levitation force and has attracted strong interest of application in maglev transportation systems, to which a linear motion drive has advantages to be incorporated. This paper presents the design and performance analysis of a linear synchronous motor drive for a levitated object by HTS bulks. The analysis results show that the developed linear motor scheme can effectively drive and control the HTS levitated transporter.
\end{abstract}

Key Words: High Temperature Superconductor, Magnetic Levitation, Maglev, Linear Motor, Motor Control

\section{INTRODUCTION}

High temperature superconductors (HTSs) become viable technically and commercially for verification to a number of practical applications. The phenomenon that a permanent magnet (PM) over a HTS bulk can produce a strong levitation force with self-stabilizing feature generates unique advantage for applications such as maglev transportation systems [1-3].

The phenomenon that a stable levitation force can be generated by a PM - e.g. NdFeB over a HTS bulk - e.g. $\mathrm{YBaCuO}$ bathed in liquid nitrogen has attracted strong interest and has been studied soon after the discovery of HTS, then intensive research has been conducted to investigate the potentials of these HTS applications, particularly in the fields of frictionless bearings such as used for flywheel energy storage and maglev transportation systems in which a linear motion drive has advantages [4,5]. The main advantage of HTS levitation is the strong levitating force with passive and self-stabilizing feature, leading to the removal of the sophisticated control system for regulating the airgap between guideway and levitated object, which is necessary for other types of levitation transportation systems. Linear motors are often used for linear motion drive, providing higher efficiency, reliability and positioning accuracy than their rotary counterparts due to the absence of movement transformation.

This paper presents the design and performance analysis of a PM linear synchronous motor (PMLSM) driving system with HTS bulks in a small-scale prototype levitator for verifications. Both the working principles of the PM-HTS bulks for lifting and the linear motor for driving the prototype levitator are described. Magnetic field finite element analysis (FEA) is conducted to accurately compute the key major parameters such as winding flux, back electromotive force (emf), inductance and cogging force. The steady state characteristic of the motor is predicted by using the classic phasor voltage equation, which can provide a reasonable result if the fundamental components of the applied voltage, back emf and current are dominant. A Matlab/Simulink-based model, which can take into account the real curves of key motor parameters against mover position, is built to predict effectively the motor's dynamic performance under a brushless dc (BLDC) control scheme, i.e. the back emf is in phase with the stator current. The simulated results include the HTS levitator moving speed controlled with the developed linear motor drive.

\section{MAGLEV AND HTS LEVITATION FORCE}

The HTS-PM lifting force is generated based on the pinning force or the shielding force of the HTS bulk [1,6]. Fig 1 shows YBaCuO HTS bulk units with $25 \mathrm{~mm}$ in diameter and $10 \mathrm{~mm}$ in height. When the materials and dimensions of the HTS and PM bulks are properly chosen, an appropriate levitation force can be generated for practical applications. One of the most attractive applications of HTS magnetic levitators is to build HTS maglev trains. Besides the HTS maglev trains, there are also a wide range of HTS levitation applications. Fig 2 shows one of HTS levitation potential applications for aerospace aircraft launching assist where a levitated airplane carrier is employed for acceleration.

The HTS levitation techniques have been verified with a practical prototype device. Fig 3 illustrates a HTS levitator principle design with a small-scale prototype having an overall size of $200 \times 50 \times 50 \mathrm{~mm}^{3}$, and an unloaded mass of $1 \mathrm{~kg}$. The interaction between the PMs mounted on the vehicle bottom and the HTS bulks placed on the ground generates the levitating forces with self-stabilizing feature, providing inherent stability in both vertical and lateral directions without the need of any active control system. The ground HTS bulks can be costly for long distance transportation. To avoid the cost, the HTS levitators can be placed in the levitated mover. 
When a HTS is applied with magnetic fields, i.e. a HTS is approached with a magnet, calculation of the reaction i.e. levitation force $\boldsymbol{F}_{\text {Lev }}$ between a PM and a HTS superconductor (SC) based on Ampere's force $\boldsymbol{f}$ is

$$
\boldsymbol{f}=q \boldsymbol{V} \times \boldsymbol{B}=\boldsymbol{J} \times \boldsymbol{B}
$$

where $q$ represents an electric charger and $\boldsymbol{V}$ is its moving velocity, $\boldsymbol{J}$ represents current density in a HTS and $\boldsymbol{B}$ is its applied magnetic flux density. Levitation force $\boldsymbol{F}_{\text {Lev }}$ therefore is given by

$$
\begin{aligned}
& \boldsymbol{F}_{L e v}=\iiint_{V_{S C}} \boldsymbol{f} d V=\iiint_{V_{S C}} d V\left(\boldsymbol{J}_{S C} \times \boldsymbol{B}\right) \\
& =\iiint_{V_{S C}} d V\left(\boldsymbol{J}_{S C} \times \boldsymbol{B}_{P M}\right)+\iiint_{d V} d V\left(\boldsymbol{J}_{S C} \times \boldsymbol{B}_{S C}\right) \\
& \because \iiint_{V_{S C}} d V\left(\boldsymbol{J}_{S C} \times \boldsymbol{B}_{S C}\right)=0 \\
& \therefore \boldsymbol{F}_{L e v}=\iiint_{V_{S C}} d V\left(\boldsymbol{J}_{S C} \times \boldsymbol{B}_{P M}\right)
\end{aligned}
$$

where $V_{S C}$ is the HTS volume, $\boldsymbol{J}_{S C}$ is supercurrent density distribution in the HTS, $\boldsymbol{B}_{P M}$ is the PM magnetic flux density as the applied magnetic field to the HTS, and $\boldsymbol{B}_{S C}$ is the magnetic flux density in the HTS. To solve the above equation, it is necessary to obtain the $\boldsymbol{B}_{P M}$ and $\boldsymbol{J}_{S C}[1]$.

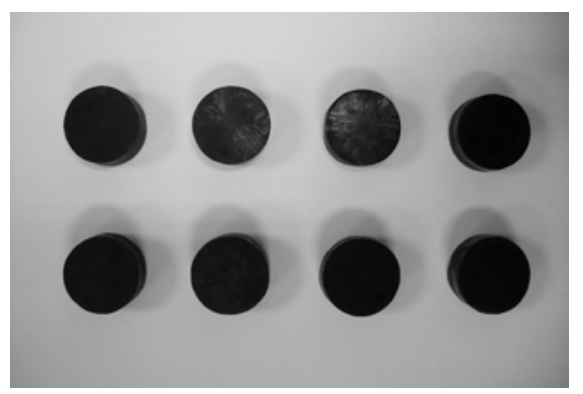

Fig 1. Levitation of a free spin PM over an HTS bulk.

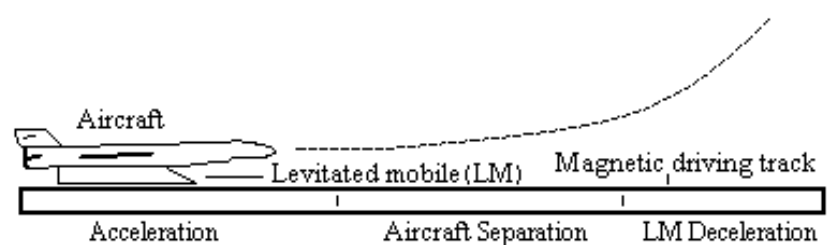

Fig 2. HTS levitated linear motion driving application in aerospace field for aircraft launching assist.

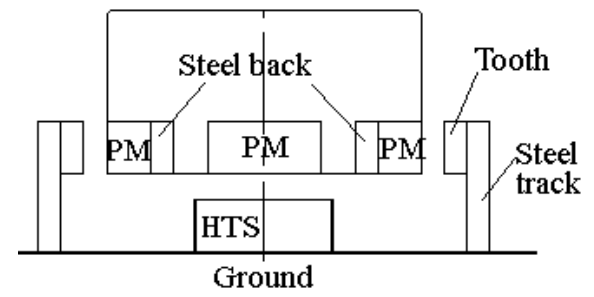

Fig 3. Schematic diagram of a linear motor driven HTS levitator scheme.

\section{LINEAR MOTOR DRIVE}

While the HTS levitation force is produced by the PM-HTS bulks, the driving force is produced by the interaction of magnetic fields of the PMs mounted on the mover sides and the currents flowing in the winds placed in the slots of stationary sidetracks. The two PMLSMs, one in each side, can be seen in Fig 3. The employment of two side motors offers the advantage that the lateral attraction force can be greatly reduced or even canceled [7]. Fig 4 plots the motor structure viewed from the top, and Table 1 lists the major dimensions and parameters.

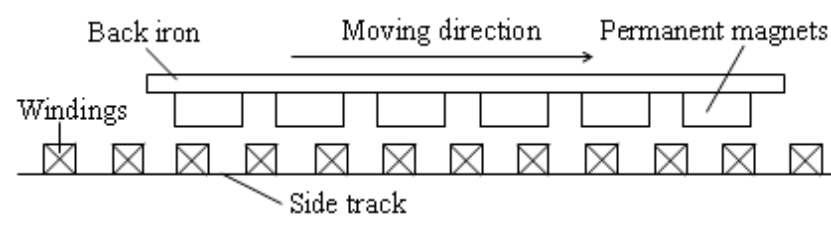

Fig 4. Top view of the PMLSM (one side).

Table1. Major Parameters and Dimensions of the PMLSM (one side)

\begin{tabular}{l|c}
\hline \hline Dimensions and parameters & Quantities \\
\hline HTS YBaCuO bulks $\phi$-25 mm and h-10 mm & 20 \\
\hline PM length (magnetization direction) $(\mathrm{mm})$ & 10 \\
\hline PM width (movement direction) $(\mathrm{mm})$ & 20 \\
\hline PM height (mm) & 10 \\
\hline Gap between adjacent PMs (mm) & 10 \\
\hline Thickness of PM back iron $(\mathrm{mm})$ & 5 \\
\hline Tooth length $(\mathrm{mm})$ & 5 \\
\hline Tooth width $(\mathrm{mm})$ & 10 \\
\hline Tooth depth (mm) & 10 \\
\hline Slot width (mm) & 10 \\
\hline Main airgap (mm) & 5 \\
\hline Number of turns of stator winding & 35 \\
\hline Diameter of copper wire $(\mathrm{mm})$ & 0.75 \\
\hline Resistance per phase $(\Omega)$ & 0.41 \\
\hline \hline
\end{tabular}

The coils wound around stator teeth are connected to form 3 phase windings, which are supplied by a standard 3-phase inverter. Only the coils facing the mover would produce the driving force, while the others only cause additional resistance, power loss and flux leakage. To deal with this problem, the coils can be divided into sections. The inverter is only connected to the active sections [7].

\section{FEA AND PARAMETER CALCULATION}

Magnetic field FEA can account for the detailed motor structure and the nonlinear properties of ferromagnetic materials and hence can accurately compute the field distribution and motor parameters. In this work, two-dimensional field computation in one pole-pair region is carried out, which is sufficient for the theoretical analysis. Three-dimensional analysis within the whole motor could be conducted for considering the fringing effect and non-symmetry among three phases, at the expense of longer computational time.

PM flux waveform, defined as the winding flux produced by the mover PMs, can be obtained from the no-load field solutions at different mover positions. To increase the computational accuracy and efficiency, the stator and mover are meshed separately from the middle of the airgap. When 
the mover moves to a specified position, the meshes are stitched along the middle airgap line. Periodical boundary conditions are applied. Fig 5 shows the PM flux versus the mover position, which is almost sinusoidal.

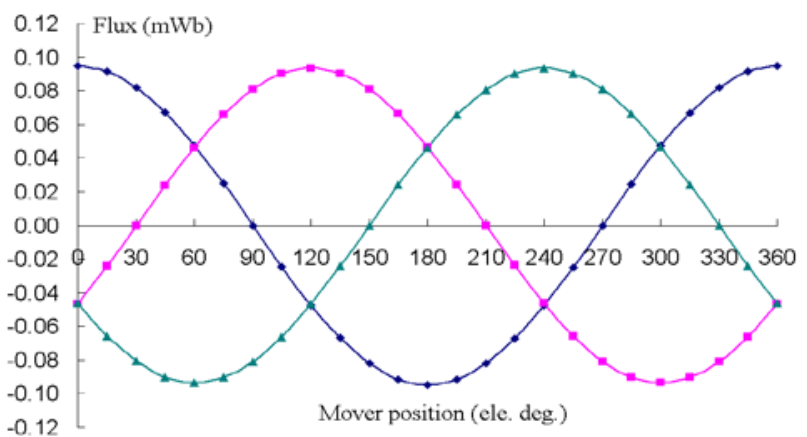

Fig 5. PM flux in one turn of one coil.

When the mover moves, an emf is induced in the stator windings. The magnitude of fundamental flux component is computed as $\phi_{1}=0.0948 \mathrm{mWb}$, so the back emf and force constants, $K_{E}$ and $K_{F}$, can be determined as $1.47 \mathrm{Vs} / \mathrm{m}$ and 4.41 N/A respectively by

$$
\begin{gathered}
K_{E}=\pi N_{e} N_{s} \phi_{1} /(\tau \sqrt{ } 2) \\
K_{F}=m K_{E}
\end{gathered}
$$

where $N_{e}=6$ is the number of active coils per phase, $N_{s}$ is the number of turns of a coil, $\tau$ is the pole pitch, and $m=3$ is the number of phases.

By using a modified incremental energy method [8], the self and mutual inductances of the three phase windings are computed as 0.163 and $0.062 \mathrm{mH}$, respectively. Due to the large effective airgap in the surface mounted PMLSM, the inductances remain constant at different mover positions.

The cogging force can be obtained from the no-load field solutions by the Virtual work or the Maxwell stress tensor method. It is found that the cogging force is negligible.

\section{STEADY-STATE CHARACTERISTIC}

When the driving motor operates in synchronous mode, its steady-state characteristic can be predicted by the phasor equation

$$
V_{1}=E_{1}+R_{1} I_{1}+j \omega_{1} L_{1} I_{1}
$$

where $V_{1}, E_{1}$ and $I_{1}$ are rms values of the applied voltage, the induced emf, and the current of a phase winding, respectively, $R_{1}$ is the phase winding resistance, $\omega_{1}$ the angular frequency, and $L_{1}$ the synchronous inductance which equals the self-inductance plus half mutual inductance here.

The motor is assumed to operate in the optimum brushless DC mode, i.e. $I_{1}$ in phase with $E_{1}$, so that the electromagnetic power and force can be calculated by

$$
\begin{gathered}
P_{e m}=m E_{1} I_{1} \\
F_{e m}=P_{e m} / v=K_{F} I_{1}
\end{gathered}
$$

where $v$ is the mover speed, and $E_{1}=K_{E} v$.

For a given terminal voltage, $V_{1}$, the relationship between the mover speed and electromagnetic force is determined by

$$
v=\frac{\sqrt{\left(\frac{R_{1} F_{e m}}{m}\right)^{2}+\left[\left(\frac{\pi L_{1} F_{e m}}{\tau K_{T}}\right)^{2}+K_{E}^{2}\right]\left[V_{1}^{2}-\left(\frac{R_{1} F_{e m}}{K_{T}}\right)^{2}\right]}-\frac{R_{1} F_{e m}}{m}}{\left(\frac{\pi L_{1} F_{e m}}{\tau K_{T}}\right)^{2}+K_{E}^{2}}
$$

Fig 6 illustrates the steady-state mechanical characteristics with different phase voltages.

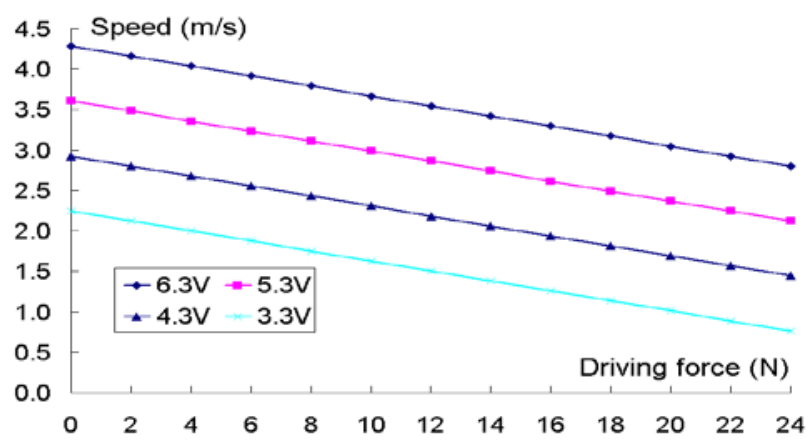

Fig 6. Steady-state mechanical characteristics of the linear motor.

\section{PERFORMANCE ANALYSIS}

The dynamic performance of the PMLSM under BLDC control can be analyzed by the following equation-based phase variable model $[9,10]$

$$
\begin{gathered}
V_{k}=r_{k} i_{k}+d \lambda_{k} / d t+e_{k}, \quad k=a, b, c \\
\lambda_{k}=\sum_{q=a}^{c} L_{k q} i_{q} \\
F_{e m}=\frac{e_{a} i_{a}+e_{b} i_{b}+e_{c} i_{c}}{v}+F_{c o g} \\
m \frac{d v}{d t}=F_{e m}-B v-F_{L}
\end{gathered}
$$

All above variables are used as their conventional meanings [10]. The profiles of $L, e$, and $F_{c o g}$ are obtained from a series of nonlinear FEA solutions, in which the mover position dependence and saturation effect can be considered.

Suppose the electrical potentials of terminals $a, b, c$ and $N$ (the neutral point) of the $\mathrm{Y}$-connected three phase windings are $U_{a}, U_{b}, U_{c}$ and $U_{N}$, respectively, one can obtain

$$
V_{k}=U_{k}-U_{N}, \quad k=a, b, c
$$

Assuming that the hard switching is applied, at the moment when phase $a$ is positively excited and phase $b$ is negatively excited, the following equations can be obtained

$$
U_{N}= \begin{cases}\frac{1}{3} \sum_{k=a}^{c}\left(U_{k}-E_{k}\right) & i_{c} \neq 0 \\ \frac{1}{2} \sum_{k=a}^{b}\left(U_{k}-E_{k}\right) & i_{c}=0\end{cases}
$$

According to (7)-(12), a Matlab/Simulink-based simulation model can be built to analyze the motor's dynamic performance as shown in Fig 7 [10]. As an example, Fig 8 illustrates the start-up speed curve of the motor with full load when the rated voltage of the inverter is applied. 


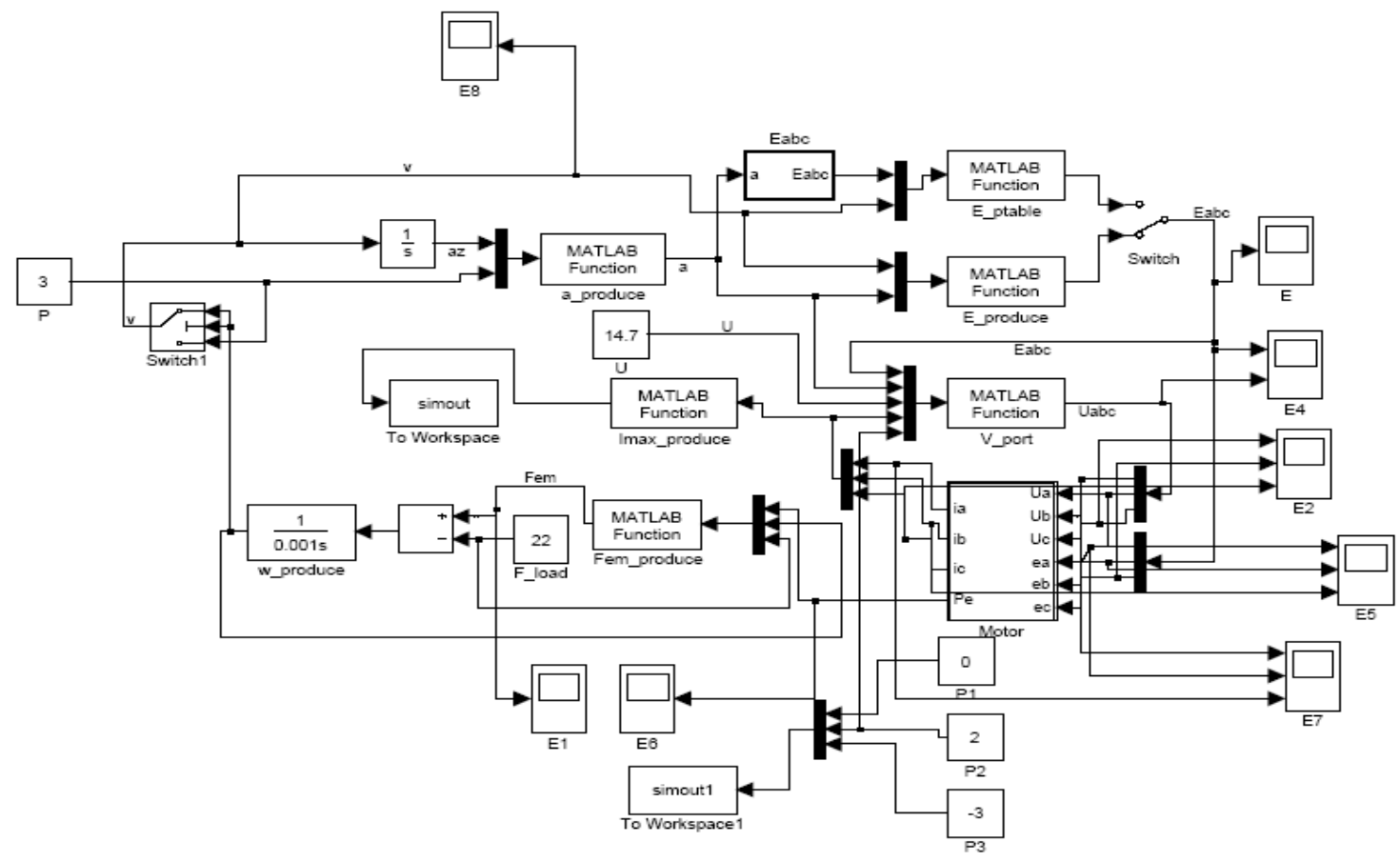

Fig 7. Matlab/Simulink-based simulation model of the BSDC motor with sinusoidal back emf.

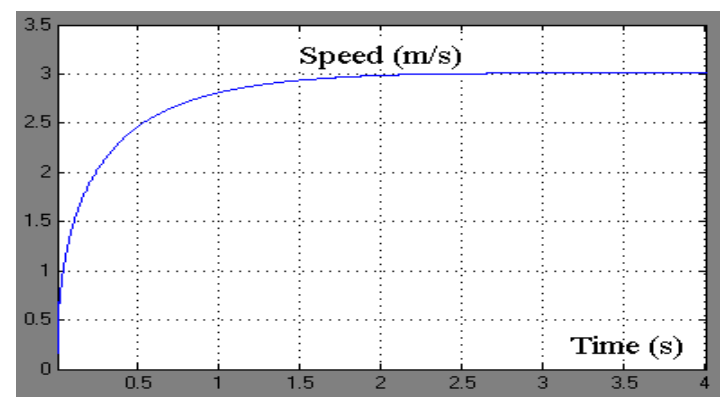

Fig 8. Speed curve during start-up.

\section{DRIVING AND CONTROL SCHEME}

The predominant nonlinear effect associated with the PMLSM is friction, which inevitably arises as long as there is relative motion between two contacting bodies, and force ripples, arising from the magnetic structure of the PMLSM and other physical imperfections. For the HTS levitation, the friction can be neglected, the predominant nonlinear effect of the PMLSM comes only from force ripples.

Owing to the typical precision requirements associated with the use of PMLSMs, it is important to handle the nonlinear effects. The force ripples, which may cause oscillation and yield instability [11], can be minimized by various control schemes. Since conventional PID (proportional-integralderivative) control usually does not suffice in high-precision and high speed application domains due to nonlinear dynamics of fiction and ripple force, some other control strategies have been applied to overcome these problems, such as $H_{\infty}$ control [12,13], PWM control [14], auto disturbance rejection control (ADRC) $[15,16]$, and some intelligent control techniques, such as fuzzy control [17], model reference adaptive control (MRAC) [18], neural networks control, adaptive fuzzy neural networks [19], robust adaptive compensation control [20].

However the above mentioned control methods are sensitive to machine parameters and deal with complicate frame transformation, and also are not easy to hardware implementation without sensors. Direct self-control and direct torque control (DTC) for induction machine were then proposed [21,22], since then papers have been published about DTC of rotating machines either induction motor or synchronous motor. The basic idea of the DTC is to control the torque and flux linkage according to the errors between given and true values, which is proceeded by selecting the space voltage vector properly. The control schema is independent of rotor parameters and implements easily without rotating reference frame transform. Fast response performance is the superiority of the DTC.

In recent years, DTC has been applied to linear motor drive, with direct thrust force control (DTFC) of linear motors. One realized sensor-less DTC propulsion control of maglev vehicle driven by the PMLSM [23], however it didn't consider end-effect. Another one is for linear induction motor (LIM), which applied the time-stepping finite element method and moving mesh technique to calculate the dynamic characteristics during DTFC [24].

End-effect is special phenomena because of limited length of armature winding. In field-oriented control, it is important that close-loop current is controlled. Thrust force ripple caused by end-effect is taken as disturb because the torque couldn't be controlled directly. The DTFC is different from mature vector control. Therefore it is important to obtain exact thrust force model. Generally it is difficult to describe the end-effect with exact mathematic model. End-effect varies with different situations and can be 
defined [25]. FEA can be conducted which is commonly used to analysis magnetic fields in the driving systems.

A DTFC scheme is considered to be incorporated with HTS PMLSM in the HTS maglev driving system. Fig 9 presents the modified DTFC system diagram implanted for the HTS PMLSM control. The electromagnetic thrust force $F_{e m}$ can be redefined as

$$
F_{e m}=\frac{3}{4} p \frac{\pi}{\tau} \frac{1}{L_{d} L_{q}\left|\psi_{s}\right|}\left[2 \psi_{f} L_{q} \sin \delta-\left|\psi_{s}\right|\left(L_{q}-L_{d}\right) \sin 2 \delta\right]
$$

where $i_{d}, i_{q}$ : d-axis and q-axis current; $\psi_{d}, \psi_{q}$ : d-axis and q-axis flux linkage; $\psi_{f}$ : HTS bulk magnet flux linkage; $L_{d}$, $L_{q}$ : d-axis and q-axis inductance; $p$ : pole pairs; $\psi_{\mathrm{s}}$ : winding flux linkage; $\delta$ : load angle. The thrust force varies with $\psi_{s}$ and $\delta$ when other parameters are taken as constant. In other words, the thrust force is to be controlled uniquely if controlling the amplitude of the $\psi_{s}$ and load angle $\delta$.

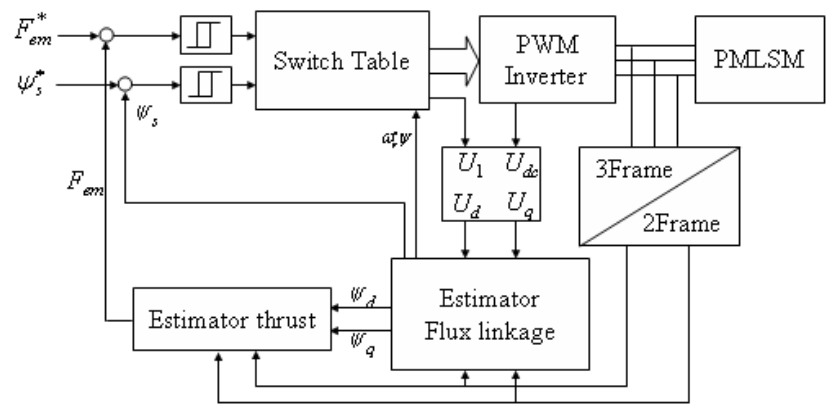

Fig 9. System diagram of a typical DTFC drive implanted for HTS LSM.

\section{REFERENCES}

[1] J. X. Jin, High $T_{C}$ superconductor theoretical models and electromagnetic flux characteristics, Journal of Electronic Sci. and Tech. of China, vol. 4, no. 3, 202-208, 2006.

[2] J. X. Jin, L. H. Zheng, R. P. Zhao, J. Zhang, L. Jiang, J. H. Chen, Y. L. Jiang, and H. Y. Zhang, Practical applications of high temperature superconductors, Nature Sciences, vol. 1, no. 1, 48-79, 2006.

[3] J. X. Jin, and L. H. Zheng, Development and applications of high temperature superconducting material, Journal of University of Electronic Science and Technology of China, vol. 35, no. 4, 612-627, 2006.

[4] F. Hellman, E. M. Gyorgy, D. W. Johnson Jr., H. M. O’Bryan, and R. C. Sherwood, Levitation of a magnet over a flat type II superconductor, J. Appl. Phys., vol. 63, pp. 447-450, 1988.

[5] J. Bankuti, I. Vajda, L. Mohacsi, A. Szalay, I. Kotsis, and M. Enisz, Design and construction of a small-scale model of a high-temperature superconducting magnetically levitated vehicle, IEEE Trans. Magn., vol. 32, no. 4, 2288-2291, 1996.

[6] T. Takao, A. Niiro, S. Suzuki, M. Hashimoto, H. Kamijo, and $\mathrm{H}$. Fujimoto, Experimental and numerical analysis of lift force in magnetic levitation system, IEEE Trans. Appl. Supercond., vol. 15, no. 2, 21281-2284, 2005.

[7] G. W. Mclean, Review of recent progress of linear motors, IEE Proceedings - B, vol. 135, no. 6, 380-416, 1988.

[8] Y. G. Guo, J. G. Zhu, and H. Y. Lu, Accurate determination of parameters of a claw pole motor with SMC stator core by finite element magnetic field analysis, IEE Proceedings Electri. Power Appl., vol. 153, no. 4, 568-574, 2006.
[9] O. A. Mohammed, S. Liu, and Z. Liu, A phase variable model of brushless dc motors based on finite element analysis and its coupling with external circuits, IEEE Tran. Magn., vol. 41, no. 5, 1576-1579, 2005.

[10] Y. G. Guo, J. G. Zhu, J. X. Chen, and J. X. Jin, Performance analysis of a permanent magnet claw pole SMC motor with brushless dc control scheme, Proc. International Power Electronics and Motion Control Conference, Shanghai, China, 11.8/1-5, 13-16 August 2006.

[11] K. K. Tan, S. Zhao; and S. Huang, Iterative reference adjustment for high-precision and repetitive motion control applications, IEEE Transactions on Control Systems Technology, vol. 13, no. 1, 83-97, 2005.

[12] D. M. Alter, and T. C. Tsao, Control of linear motors for machine tool feed drives: Design and implementation of $\mathrm{H}_{\infty}$ optimal feedback control, ASME J. Dyn. Syst. Maes. Contr., vol. 118, 649-658, 1996.

[13] Y. F. Tian, and Q. D. Guo, Study on robustness-tracking control for linear servo system, The 4th International on Power Electronics and Motion Control Conference (IPEMC 2004), vol. 2, 1060-1064, 14-16 August 2004.

[14] K. K. Tan, T. H. Lee, H. Dou, and S. J. Chin, PWM modeling and application to disturbance observer-based precision motion control, International Conf. on Power Sys. Technology, vol. 3, 1669-1674, 4-7 December 2000.

[15] J. Yang, N. C. Cheung, and J. Wu, The auto-disturbance rejection controller for speed regulation in permanentmagnet linear motors, Industrial Electronics Society, 2004; 30th Annual Conf. IEEE, vol. 2, 1123-1127, 2-6 Nov. 2004.

[16] C. Lei, J. Wu, Y. Chen, and J. Yang, Permanent-magnet linear motor control system based on the auto-disturbancerejection controller, $6^{\text {th }}$ Int. Conf. Electrical Machines and Systems (ICEMS 2003), vol. 1, 62-65, 9-11 Nov. 2003.

[17] Y. P. Chen, D. L. Zhang, W. Ai, Z. D. Zhou, and L. Y. Liu, An improved fuzzy system for position control of permanent magnet linear motor, Proceedings of 2005 International Conference on Machine Learning and Cybernetics, vol. 5, 2731-2735, 18-21 August 2005.

[18] Y. R. Chen, J, Wu, and N. C. Cheung, Lyapunov's stability theory-based model reference adaptive control for permanent magnet linear motor drives, Proceedings of 2004 First International Conference on Power Electronics Systems and Applications, 260-266, 9-11 November 2004.

[19] F. J. Lin, and P. H. Shen, A DSP-based permanent magnet linear motor servo drive using adaptive fuzzy-neuralnetwork control, IEEE Conf. on Robotics, Automation and Mechatronics, vol. 1, 601-606, 1-3 December 2004.

[20] K. K. Tan, S. N. Huang, and T. H. Lee, Robust adaptive numerical compensation for friction and force ripple in permanent-magnet linear motors, IEEE Transactions on Magnetics, vol. 38, no. 1, 221-228, 2002.

[21] M. Depenbrock, Direct self-control (DSC) of inverter-fed induction machine, IEEE Transactions on Power Electronics, vol. 3, no. 4, 420-429, 1988.

[22] I. Takahashi, and T. Naguchi, A new quick-response and high-efficiency control strategy of an induction motor, IEEE Tran. Industry Application, vol. 22, no. 5, 820-827, 1986.

[23] K. Yoshida, Z. Dai, and M. Sato, Sensorless DTC propulsion control of PM LSM vehicle, Proceedings of the $3^{\text {rd }}$ International Power Electronics and Motion Control Conference (IPEMC 2000), vol. 1, 191-196, August 2000.

[24] B. I. Kwon, K. I. Woo, and S. Kim, Finite element analysis of direct thrust-controlled linear induction motor, IEEE Tran. Magnetics, vol. 35, no. 3, 1306-1309, 1999.

[25] J. F. Cui, C. Y. Wang, J. Y. Yang, and L. F. Liu, Analysis of direct thrust force control for permanent magnet linear synchronous motor, Proceedings of $5^{\text {th }}$ World Congress on Intelligent Control and Automation (WCICA 2004), vol. 5, 4418-4421, 15-19 June 2004. 